\title{
"They Wanted to Talk to a 'Real Doctor'": Predictors, Perpetrators, and Experiences of Racial and Ethnic Discrimination Among Healthcare Workers
}

\author{
Rachel Hennein, $B S^{1,2}{ }^{(0)}$, Petty Tineo, $M A^{3}$, Jessica Bonumwezi, $M A^{3}$, \\ Hannah Gorman, BA ${ }^{4}$, Max Jordan Nguemeni Tiako, $M D^{7}$, and Sarah R. Lowe, $P h D^{4}$
}

${ }^{1}$ Yale School of Medicine, Yale University, New Haven, CT, USA; ${ }^{2}$ Department of Epidemiology of Microbial Diseases, Yale School of Public Health, Yale University, 60 College St, New Haven, CT, USA; ${ }^{3}$ Department of Psychology, Montclair State University, Montclair, NJ, USA; ${ }^{4}$ Department of Social and Behavioral Sciences, Yale School of Public Health, Yale University, New Haven, CT, USA.

BACKGROUND: Racial and ethnic diversity of healthcare workers have benefits on team functioning and patient care. However, a significant barrier to retaining diverse providers is discrimination.

OBJECTIVE: To assess the predictors, perpetrators, and narratives of racial discrimination among healthcare workers.

DESIGN: Survey study.

PARTICIPANTS: Healthcare workers employed at academic hospitals.

MAIN MEASURES: We assessed prevalence and perpetrators of racial and ethnic discrimination using the General Ethnic Discrimination Scale. We included an open-ended question asking respondents to recount experiences of discrimination and analyzed responses using grounded theory.

KEY RESULTS: Of the 997 participants, $12.2 \%$ were females from backgrounds underrepresented in medicine (URM), 4.0\% URM males, 10.1\% Asian females, 4.7\% Asian males, 49.1\% non-Hispanic White females, and 19.8\% non-Hispanic White males. Among healthcare workers of color, $85.2 \%$ reported discrimination. Over half of URM females (51.4\%), URM males (52.6\%), and Asian females $(62.5 \%)$ reported discrimination by patients. About 20-25\% of URM females, URM males, and Asian females reported discrimination by teachers, supervisors, co-workers, and institutions. In adjusted binary logistic models, URM females had 10.14 odds (95\% confidence interval [95\%CI]: 5.13, 20.02, $p<.001)$, URM males 6.23 odds (95\%CI: 2.59, 14.98, $p<.001)$, Asian females 7.90 odds (95\%CI: 4.07, 15.33, $p<.001)$, and Asian males 2.96 odds (95\% CI: 1.47, 5.97, $p=.002)$ of reporting discrimination compared with non-Hispanic White males. Needing more support was associated with 2.51 odds (95\% CI: 1.54, 4.08, $p<.001$ ) of reporting discrimination. Our qualitative findings identified that the murder of George Floyd intensified URM healthcare workers' experiences of discrimination through increased fear of violence and requests for unpaid diversity work. Asian healthcare workers reported that pandemic-related anti-Asian violence shaped their experiences of discrimination through increased fear of violence and care refusal from patients.

Received May 4, 2021

Accepted September 8, 2021

Published online September 24, 2021
CONCLUSIONS: Our findings provide insights into experienced discrimination among healthcare workers and opportunities for hospitals to create programs that improve inclusivity.

KEY WORDS: discrimination; race and ethnicity; bias; healthcare workers.

J Gen Intern Med 37(6):1475-83

DOI: $10.1007 / \mathrm{s} 11606-021-07143-3$

(C) Society of General Internal Medicine 2021

\section{INTRODUCTION}

Racial and ethnic diversity among healthcare workers (HCWs) have substantial benefits to team functioning and patient care. ${ }^{1-3}$ However, racism and ethnic discrimination threaten the diversity of the healthcare workforce, and have been associated with decreased opportunities for career advancement ${ }^{4-6}$ and increased job turnover. ${ }^{7}$ Racism and ethnic discrimination occur when the dominant racial and/or ethnic group uses its power to devalue and limit access to resources to groups that they define as inferior. ${ }^{8}$ Racism and ethnic discrimination within the health workforce occur at multiple levels, including structural racism within medical institutions ${ }^{9}$ and individual-level discrimination from colleagues and patients. $^{1}$

The prevalence of racial and ethnic discrimination among HCWs of color, i.e., HCWs who do not identify as nonHispanic White, ranges from 22 to $71 \% .^{1,10-12}$ Studies have suggested that female HCWs of color face unique discrimination experiences due to their "double minority" status - as both a HCW of color and female provider..$^{1,7,13,14}$ Yet, the most recent study from a 2020 systematic review of discrimination among HCWs included data collected in 2009. ${ }^{1,12}$ More recent studies are warranted to understand how experienced racism and ethnic discrimination have changed, especially during times of heightened violence against communities of color. For example, during the COVID-19 pandemic, there were over 2800 hate crimes targeting Asian Americans in the United States (US) from March to December 2020. ${ }^{15}$ There were also several publicized police killings of unarmed Blacks/African Americans in 2020. ${ }^{16}$ Individuals who identify 
as a member of these races and ethnicities, but who are not directly involved in the traumatic event, may experience vicarious discrimination. ${ }^{8}$ For example, studies have identified that publicized police violence against people of color is associated with subsequent heightened discrimination among members of these racial and ethnic groups. ${ }^{17,18}$

HCWs of color have spoken out about how they are impacted by national violence against their communities. ${ }^{19,20}$ However, no empirical studies to date have examined racial and ethnic discrimination among HCWs during this time. Thus, we conducted a survey study of HCWs to identify the perpetrators, predictors, and experiences of racial and ethnic discrimination throughout the year 2020. By studying experienced discrimination among HCWs quantitatively and qualitatively, we aimed to provide insights into the magnitude of discrimination, as well as the lived experiences of those impacted.

\section{METHODS}

\section{Setting and Recruitment}

This cross-sectional study is part of a larger survey study that assessed factors related to $\mathrm{HCW}$ well-being during the COVID-19 pandemic. The online survey was administered from December 1, 2020, to January 14, 2021, to 24 hospitals located in 12 states with high rates of COVID-19 transmission. ${ }^{21}$ We emailed department and affinity group leaders to request that they forward our survey to their staff. We required that participants were at least 18 years of age and worked at a clinic/hospital. The Yale Institutional Review Board approved our study procedures.

\section{Data Collection Tool}

We designed the survey to assess factors associated with selfreported discrimination quantitatively and capture the experiences of discrimination qualitatively. The survey was anonymous to encourage respondents to report their experiences honestly.

Demographic Variables. Demographic data collected included age; gender (male, female, non-binary, transgender male, transgender female, and other); race; ethnicity; marital status; profession; and income. Following Pololi et al., ${ }^{12}$ we categorized race and ethnicity by grouping together respondents who were from backgrounds underrepresented in medicine (URM), including those who were Black/ African American, Hispanic/Latino(a), American Indian/ Alaskan Native, and/or Native Hawaiian/Pacific Islander, ${ }^{22}$ and maintaining separate categories for Asian and nonHispanic White participants. Given studies that identified discrimination experiences to be influenced by the intersection of race, ethnicity, and gender, ${ }^{1}$ we categorized participants based on intersecting identities, including URM females, URM males, Asian females, Asian males, non-Hispanic White females, and non-Hispanic White males. This analysis was notably limited by insufficient power to create appropriate intersecting categories for transgender and non-binary participants and our use of sex-based gender indicators.

Discrimination. We used the General Ethnic Discrimination Scale to assess discrimination, ${ }^{23}$ including 18 items asking about the frequency of various experiences of racial and ethnic discrimination from January 2020 to 2021 . We included an additional item asking respondents how often they faced discrimination by patients. ${ }^{24}$ Each item was assessed on a 6-point scale, from "never" (scored as 1) to "almost all the time" (scored as 6). Participants could select "N/A" if the item was not applicable to them. We created a dichotomous variable for experiencing any racial discrimination based on previous studies that transformed ordinal discrimination scores into a dichotomous indicator. ${ }^{1,7,10,11}$ Participants were classified as having experienced any discrimination if they had a numeric response greater than 1 on any item. We also created dichotomous indicators for the 10 items asking about perpetrators of discrimination; participants were classified as having experienced perpetrator-specific discrimination if their response was greater than 1 on the perpetratorspecific item. This scale has been validated for use among Black/African American, Hispanic/Latino(a), Asian, and White respondents. ${ }^{23} \mathrm{We}$ also included an open-ended question asking respondents to share any experience of racial and ethnic discrimination in the last year.

Social Support. As research has identified an inverse relationship between social support and perceived discrimination, ${ }^{1}$ we employed one item from the National Health and Nutrition Examination Survey to measure social support needs. ${ }^{25}$ We also evaluated social support within the hospital by assessing self-reported team cohesion using the Survey of Organizational Attributes for Primary Care. ${ }^{26,27}$

\section{Data Analysis}

Quantitative Analysis. First, we conducted a missing data analysis by comparing respondents in the analytic sample with those who were dropped due to missing data using independent-samples $t$-tests and chi-square analyses. We used unadjusted generalized linear models to assess differences in the prevalence of any discrimination as well as discrimination by each perpetrator type, with Bonferroni-corrected post hoc tests to assess pairwise differences between intersecting identity categories. We ran unadjusted and adjusted binary logistic regression models, with intersecting identity group category (reference $=$ non-Hispanic White male), other demographic characteristics, and social support predicting the odds of reporting any discrimination. We conducted an adjusted 
generalized linear model with Bonferroni-corrected post hoc tests to assess differences in the prevalence of discrimination between each pair of intersecting identity categories. Analyses were conducted in SPSS 27.0 (IBM Corp., 2020). We considered $p<.05$ to be statistically significant. We used the Strengthening the Reporting of Observational Studies in Epidemiology (STROBE) ${ }^{28}$ and the Consolidated Criteria for Reporting Qualitative Research (COREQ) ${ }^{29}$ reporting guidelines for the quantitative and qualitative analyses, respectively.

Qualitative Analysis. We coded the responses to the openended question asking about experiences of racial and ethnic discrimination using grounded theory. ${ }^{30}$ The coders included a female, mixed-race (Black/White) public health doctoral student (RH), a female, Black clinical psychology doctoral candidate (JB), and a female, Hispanic clinical psychology doctoral candidate (PT). Each coder read all responses, and then met together to define inductive codes based on constructs that emerged from the data. For example, the code "assumptions about profession" was applied when respondents described that they were assumed to have a different profession based on their race and/or ethnicity. Following codebook development, we independently coded random sets of 50 open-ended responses until we reached Cohen's kappa $>.80 .{ }^{31}$ After each coding set, we met to compare codes and further refine the codebook. Once we achieved kappa $>.80$, we independently coded all responses and calculated a final statistic. Coders met to discuss any discrepancies until consensus was met, generating the final coded data file. Lastly, we discussed cross-code themes using thematic content analysis, and reported all themes irrespective of their frequency in the data. ${ }^{32} \mathrm{We}$ discussed how our own positionality could influence our analysis of the data throughout the coding process. ${ }^{33}$

\section{RESULTS}

\section{Study Sample}

Of the 997 included participants with complete data, 122 (12.2\%) were URM female, 40 (4.0\%) URM male, 101 (10.1\%) Asian female, 47 (4.7\%) Asian male, 490 (49.1\%) non-Hispanic White female, and 197 (19.8\%) non-Hispanic White male (Table 1). The mean age was 38.22 years (standard deviation $[S D]=11.77)$. Among the 1053 respondents who took the survey, we excluded $52(4.9 \%)$ due to incomplete surveys and $4(0.4 \%)$ who identified as transgender or non-binary given insufficient power to create appropriate intersecting identity categories. There were no significant differences among participants in the analytic sample $(n=997)$ and participants who were dropped $(n=56)$.
Table 1 Participant Characteristics

\begin{tabular}{|c|c|c|}
\hline Characteristic & $n(\%)$ & $\begin{array}{l}\text { Mean } \\
\text { (SD) }\end{array}$ \\
\hline Age & - & $\begin{array}{l}38.22 \\
(11.77)\end{array}$ \\
\hline \multicolumn{3}{|l|}{ Intersecting identities } \\
\hline URM female & $\begin{array}{l}122 \\
(12.2)\end{array}$ & - \\
\hline Non-Hispanic Black female & $66(6.6)$ & - \\
\hline Hispanic White female & 49 (4.9) & - \\
\hline Hispanic Black female & $3(0.3)$ & - \\
\hline Non-Hispanic American Indian/Alaskan & $4(0.4)$ & - \\
\hline \multicolumn{3}{|l|}{$\begin{array}{l}\text { Native, and/or Native Hawaiian/Pacific Is- } \\
\text { lander female }\end{array}$} \\
\hline URM male & $40(4.0)$ & - \\
\hline Non-Hispanic Black male & $18(1.8)$ & - \\
\hline Hispanic White male & $21(2.1)$ & - \\
\hline Non-Hispanic American Indian/Alaskan & $1(0.1)$ & - \\
\hline \multicolumn{3}{|l|}{$\begin{array}{l}\text { Native, and/or Native Hawaiian/Pacific Is- } \\
\text { lander male }\end{array}$} \\
\hline Non-Hispanic Asian female & $\begin{array}{l}101 \\
(10.1)\end{array}$ & - \\
\hline Non-Hispanic Asian male & $47(4.7)$ & - \\
\hline Non-Hispanic White female & $\begin{array}{l}490 \\
(49.1)\end{array}$ & - \\
\hline Non-Hispanic White male & $\begin{array}{l}197 \\
(19.8)\end{array}$ & - \\
\hline \multicolumn{3}{|l|}{ Marital status } \\
\hline Married & $\begin{array}{l}552 \\
(55.4)\end{array}$ & - \\
\hline Single & $\begin{array}{l}392 \\
(39.3)\end{array}$ & - \\
\hline Divorced/widowed & $53(5.3)$ & - \\
\hline \multicolumn{3}{|l|}{ Household income } \\
\hline$<\$ 10,000$ & $61(6.1)$ & - \\
\hline$\$ 10,000$ to $\$ 24,999$ & $21(2.1)$ & - \\
\hline$\$ 25,000$ to $\$ 49,999$ & $62(6.2)$ & - \\
\hline$\$ 50,000$ to $\$ 74,999$ & $\begin{array}{l}173 \\
(17.4)\end{array}$ & - \\
\hline$\$ 75,000$ to $\$ 99,999$ & $\begin{array}{l}114 \\
(11.4)\end{array}$ & - \\
\hline$\$ 100,000$ to $\$ 149,999$ & $\begin{array}{l}137 \\
(13.7)\end{array}$ & - \\
\hline$\$ 150,000$ to $\$ 199,999$ & $\begin{array}{l}110 \\
(11.0)\end{array}$ & - \\
\hline$\$ 200,000$ to 299,999 & $\begin{array}{l}130 \\
(13.0)\end{array}$ & - \\
\hline$>\$ 300,000$ & $\begin{array}{l}189 \\
(19.0)\end{array}$ & - \\
\hline \multicolumn{3}{|l|}{ Profession } \\
\hline Physician & $\begin{array}{l}318 \\
(31.9)\end{array}$ & - \\
\hline Trainee & $\begin{array}{l}280 \\
(28.1)\end{array}$ & - \\
\hline Nurse & $\begin{array}{l}125 \\
(12.5)\end{array}$ & - \\
\hline Health technician & $76(7.6)$ & - \\
\hline Physician, nursing, medical assistant & $47(4.7)$ & - \\
\hline Other clinical & $86(8.6)$ & - \\
\hline Other non-clinical & $65(6.5)$ & - \\
\hline \multicolumn{3}{|l|}{ Support needs } \\
\hline None & $\begin{array}{l}297 \\
(29.8)\end{array}$ & - \\
\hline A little & $\begin{array}{l}261 \\
(26.2)\end{array}$ & - \\
\hline Some & $\begin{array}{l}284 \\
(28.5)\end{array}$ & - \\
\hline A lot & $\begin{array}{l}155 \\
(15.5)\end{array}$ & - \\
\hline Team cohesion & - & $\begin{array}{l}24.87 \\
(4.57)\end{array}$ \\
\hline
\end{tabular}

$S D$, standard deviation; URM, underrepresented in medicine URM includes Black/African American, Hispanic/Latino(a), American Indian/Alaskan Native, and/or Native Hawaiian/Pacific Islander respondents 


\section{Prevalence, Perpetrators, and Predictors of Discrimination}

Over half of all HCWs (57.7\%) reported racial discrimination, including $90.2 \%$ of URM females, $87.1 \%$ of Asian females, $82.5 \%$ of URM males, $70.2 \%$ of Asian males, $46.2 \%$ of nonHispanic White males, and $44.9 \%$ of non-Hispanic White females (Table 2). Among HCWs of color, 85.2\% reported experiencing racial and/or ethnic discrimination. In pairwise comparisons, the prevalence of racial discrimination was significantly more common among URM females, URM males, Asian females, and Asian males, compared with non-Hispanic White males and females.

All HCWs of color were significantly more likely to report discrimination from patients compared with non-Hispanic White males and females (Table 2). Over half of URM females (51.4\%), URM males (52.6\%), and Asian females (62.5\%) and almost half of Asian males (46.7\%) reported racial discrimination from patients. Furthermore, $22.1 \%$ of URM females, $23.3 \%$ of URM males, $21.5 \%$ of Asian females, and $24.4 \%$ of Asian males reported discrimination by teachers/ professors, compared with less than $5 \%$ of non-Hispanic White HCWs.

Compared with non-Hispanic White HCWs, URM females, URM males, and Asian females were significantly more likely to report discrimination from employers, co-workers, and institutions. Discrimination from employers was reported by $25.2 \%$ of URM females, $31.6 \%$ of URM males, $23.2 \%$ of Asian females, and $17.0 \%$ of Asian males, compared with 3$7 \%$ of non-Hispanic White HCWs. Similarly, 25.4\% of URM females, $28.2 \%$ of URM males, $20.2 \%$ of Asian females, and $12.8 \%$ of Asian males experienced discrimination from their co-workers, compared with about $6 \%$ of non-Hispanic White HCWs. Discrimination from institutions (e.g., schools, universities, and the police) was reported by $25.9 \%$ of URM females, $25.6 \%$ of URM males, $19.4 \%$ of Asian females, and $14.9 \%$ of Asian males, compared with less than $5 \%$ of non-Hispanic White HCWs.

The results of unadjusted and adjusted binary logistic models predicting the odds of reporting racial discrimination are shown in Table 3. Nagelkerke's $R^{2}$ for the fully adjusted model was 0.232 . Compared with nonHispanic White males, URM females had 10.14 odds (95\% confidence interval [95\%CI]: 5.13, 20.02, $p<.001$ ), URM males 6.23 odds (95\%CI: 2.59, 14.98, $p<.001)$, Asian females 7.90 odds (95\%CI: 4.07, 15.33, $p<.001$ ), and Asian males 2.96 odds (95\%CI: 1.47, 5.97, $p=.002$ ) of reporting racial discrimination. Needing a lot more social support, compared with not needing any additional support, was associated with 2.51 odds (95\%CI: 1.54 , $4.08, p<.001)$ of reporting discrimination. Post hoc tests showed that non-Hispanic White males were significantly less likely to report discrimination than URM males $(p<.001)$, URM females $(p<.001)$, Asian males $(p=.01)$, and Asian females $(p<.001)$. Furthermore, post hoc tests showed that non-Hispanic White females were significantly less likely to report discrimination compared with URM males $(p<.001)$, URM females $(p<.001)$, Asian males $(p=.001)$, and Asian females $(p<.001)$.

Table 2 Prevalence and Perpetrators of Racial Discrimination Among Healthcare Workers

\begin{tabular}{|c|c|c|c|c|c|c|c|c|c|}
\hline Perpetrator & $n^{*}$ & $\begin{array}{l}\text { Overall } \\
\text { sample, \% }\end{array}$ & $\begin{array}{l}\text { URM } \\
\text { female, } \\
\%\end{array}$ & $\begin{array}{l}\text { URM } \\
\text { male, \% }\end{array}$ & $\begin{array}{l}\text { Asian } \\
\text { female, } \\
\%\end{array}$ & $\begin{array}{l}\text { Asian } \\
\text { male, \% }\end{array}$ & $\begin{array}{l}\text { Non-Hispanic } \\
\text { White female, } \\
\%\end{array}$ & $\begin{array}{l}\text { Non-Hispanic } \\
\text { White male, } \\
\%\end{array}$ & $\begin{array}{l}\text { Wald chi- } \\
\text { square, } p \\
\text { value }\end{array}$ \\
\hline Overall prevalence & 997 & 57.7 & $90.2_{\mathrm{a}, \mathrm{b}}$ & $82.5_{a, b}$ & $87.1_{\mathrm{a}, \mathrm{b}}$ & $70.2 \mathrm{a}, \mathrm{b}$ & 44.9 & 46.2 & $<.001$ \\
\hline \multicolumn{10}{|c|}{ Prevalence by perpetrators } \\
\hline $\begin{array}{l}\text { Teachers and } \\
\text { professors }\end{array}$ & 786 & 8.1 & $22.1_{\mathrm{a}, \mathrm{b}}$ & 23.3 & $21.5_{\mathrm{a}, \mathrm{b}}$ & $24.4_{b}$ & 1.5 & 4.2 & $<.001$ \\
\hline $\begin{array}{l}\text { Employers, bosses, } \\
\text { and supervisors }\end{array}$ & 981 & 10.4 & $25.2_{\mathrm{a}, \mathrm{b}}$ & $31.6_{\mathrm{a}, \mathrm{b}}$ & $23.2 \mathrm{a}, \mathrm{b}$ & 17.0 & 3.3 & 7.1 & $<.001$ \\
\hline $\begin{array}{l}\text { Co-workers, fellow } \\
\text { students, and } \\
\text { colleagues }\end{array}$ & 985 & 10.8 & $25.4_{a, b}$ & $28.2_{\mathrm{a}, \mathrm{b}}$ & $20.2_{\mathrm{a}, \mathrm{b}}$ & 12.8 & 5.6 & 6.1 & $<.001$ \\
\hline Patients & 955 & 28.0 & $51.4_{\mathrm{a}, \mathrm{b}}$ & $52.6 \mathrm{a}, \mathrm{b}$ & $62.5 \mathrm{a}, \mathrm{b}$ & $46.7 \mathrm{a}, \mathrm{b}$ & 16.3 & 16.9 & $<.001$ \\
\hline $\begin{array}{l}\text { People in service } \\
\text { jobs (e.g., store } \\
\text { clerks) }\end{array}$ & 992 & 17.7 & $45.0 \mathrm{a}, \mathrm{b}$ & $37.5 \mathrm{a}, \mathrm{b}$ & $39.0 \mathrm{a}, \mathrm{b}$ & $27.7 \mathrm{~b}$ & 8.0 & 8.1 & $<.001$ \\
\hline Strangers & 991 & 25.6 & $30.5 \mathrm{a}, \mathrm{b}$ & $51.3_{\mathrm{a}, \mathrm{b}}$ & $57.0_{\mathrm{a}, \mathrm{b}}$ & $46.8_{\mathrm{a}, \mathrm{b}}$ & 10.6 & 15.2 & $<.001$ \\
\hline $\begin{array}{l}\text { People in helping } \\
\text { jobs (e.g., personal } \\
\text { doctors) }\end{array}$ & 992 & 9.0 & $27.7_{\mathrm{a}, \mathrm{b}}^{\mathrm{b}}$ & $22.5^{\circ}$ & $17.0_{\mathrm{a}, \mathrm{b}}^{\mathrm{a}, \mathrm{b}}$ & $14.9^{a}$ & 3.1 & 4.1 & $<.001$ \\
\hline Neighbors & 991 & 9.2 & $28.6 \mathrm{a}, \mathrm{b}$ & 22.5 & $17.3 \mathrm{a,b}$ & 17.0 & 3.3 & 3.6 & $<.001$ \\
\hline $\begin{array}{l}\text { Institutions (e.g., } \\
\text { schools, universities, } \\
\text { the police) }\end{array}$ & 965 & 9.1 & $25.9 \mathrm{a}, \mathrm{b}$ & $25.6_{a, b}$ & $19.4_{\mathrm{a}, \mathrm{b}}$ & 14.9 & 3.0 & 4.6 & $<.001$ \\
\hline Friends & 989 & 9.6 & $24.4_{\mathrm{a}, \mathrm{b}}$ & $25.0_{\mathrm{a}}$ & $18.4_{\mathrm{a}, \mathrm{b}}$ & 8.5 & 5.3 & 4.1 & $<.001$ \\
\hline
\end{tabular}

For pairwise comparisons with Bonferroni-corrected $p$ values $<.05$, ${ }_{a}$ represents significantly higher than non-Hispanic White males and ${ }_{b}$ represents significantly higher than non-Hispanic White females

* For each perpetrator type, values are less than the overall sample of 997 because respondents were asked to respond only to those items that were applicable to them

URM, underrepresented in medicine

URM includes Black/African American, Hispanic/Latino(a), American Indian/Alaskan Native, and/or Native Hawaiian/Pacific Islander respondents 
Table 3 Predictors of Reporting Any Racial Discrimination in the Overall Sample

\begin{tabular}{|c|c|c|}
\hline & Unadjusted model & Adjusted model \\
\hline & OR $(95 \% \mathrm{CI})$ & OR $(95 \% \mathrm{CI})$ \\
\hline \multicolumn{3}{|l|}{ Intersecting identities } \\
\hline Non-Hispanic White male (reference) & 1.00 & 1.00 \\
\hline Non-Hispanic White female & $1.05(0.76,1.47)$ & $0.99(0.62,1.30)$ \\
\hline URM female & $11.25(6.04,20.95) * * *$ & $10.14(5.13,20.02)^{* * *}$ \\
\hline URM male & $5.79(2.51,13.33) * * *$ & $6.23(2.59,14.98)^{* * *}$ \\
\hline Asian female & $8.31(4.52,15.27)^{* * *}$ & $7.90(4.07,15.33) * * *$ \\
\hline Asian male & $2.89(1.51,5.54)^{* *}$ & $2.96(1.47,5.97)^{* *}$ \\
\hline \multirow{2}{*}{\multicolumn{3}{|c|}{ Marital status }} \\
\hline & & \\
\hline Married (reference) & 1.00 & 1.00 \\
\hline Single & $1.37(1.05,1.78)^{*}$ & $1.18(0.81,1.72)$ \\
\hline Divorced/widowed & $1.51(0.84,2.72)$ & $1.37(0.71,2.66)$ \\
\hline Household income & $0.96(0.91,1.01)$ & $1.00(0.91,1.10)$ \\
\hline \multicolumn{3}{|l|}{ Profession } \\
\hline Physician (reference) & 1.00 & 1.00 \\
\hline Trainee & $1.17(0.84,1.62)$ & $0.79(0.48,1.30)$ \\
\hline Nurse & $0.79(0.52,1.20)$ & $0.83(0.51,1.36)$ \\
\hline Health technician & $0.83(0.50,1.38)$ & $0.65(0.35,1.21)$ \\
\hline Physician, nursing, medical assistant & $0.89(0.48,1.64)$ & $0.71(0.34,1.48)$ \\
\hline Other clinical & $1.03(0.64,1.68)$ & $1.08(0.60,1.94)$ \\
\hline Other non-clinical & $0.65(0.38,1.11)$ & $0.58(0.30,1.11)$ \\
\hline \multicolumn{3}{|l|}{ Support needs } \\
\hline None (reference) & 1.00 & 1.00 \\
\hline A little & $1.10(0.79,1.53)$ & $1.21(0.83,1.75)$ \\
\hline Some & $1.18(0.85,1.64)$ & $1.45(0.99,2.12)$ \\
\hline A lot & $2.60(1.70,3.98)^{* * *}$ & $2.51(1.54,4.08)^{* * *}$ \\
\hline Team cohesion & $0.98(0.95,1.00)$ & $0.99(0.95,1.02)$ \\
\hline
\end{tabular}

$* * * p<0.001 ; * * p<0.01$ and $\geq 0.001 ; * p<0.05$ and $\geq 0.01$

URM, underrepresented in medicine; OR, odds ratio

URM includes Black/African American, Hispanic/Latino(a), American Indian/Alaskan Native, and/or Native Hawaiian/Pacific Islander respondents

\section{Experienced Discrimination Among URM HCWs}

URM HCWs reported experiencing discrimination throughout their workday. Upon entering the hospital, URM HCWs described disproportionate and excessive monitoring by security, a theme we termed Excessive Monitoring. A Black/African American, female $\mathrm{HCW}$ described:

Being interrogated by screeners at the hospital front doors every day I come in for work. Asking to see my badge, when I've witnessed them fail to ask white colleagues for their badges.

Another theme that we identified was Constant Microaggressions. Microaggressions are cues that communicate insults towards members of a marginalized group, in this case people of color. ${ }^{34}$ URM HCWs reported that hospital staff assumed that they had a different role based on their race, which resulted in being overlooked and excluded in the hospital. This was especially true among URM females, who reported that the combination of their gender and race impacted how people treated them in the hospital. A female, Black/ African American HCW explained:

Patients, nurses, technicians, residents, other attending physicians always assume I am a nurse, based primarily on gender, age, and race I would imagine- it happens countless times per day...I am either ignored or overlooked or just not included on first meeting with most professionals. Patients generally just ask when they will see the doctor.

Many URM HCWs reported that they withstood microaggressions, as confronting them would take up a significant amount of time and energy. When they did confront staff about microaggressions, URM HCWs' lived experiences were dismissed. A male, Black/ African American HCW described:

I had not cut my hair during the first three months of the pandemic. My hair was long and one of my therapy colleagues told me she wanted to comb my hair. I was sitting at a computer a couple minutes later and she came and combed my hair. I told her it was a microaggression. She apologized with a giggle and then walked away.

Another theme that we identified was Unfair Pay/Promotion, based on Black/African American HCWs' perceptions of being differentially allocated compensation and promotion opportunities based on their race. A female, Black/African American HCW described:

I was passed over for a promotion to someone of the other race even though I had more experience. Denied 
pay increase or compensation for taking on extra duties.

This respondent suggests that URM HCWs face two barriers to receiving higher pay: (1) decreased opportunities for higher paying positions and (2) lack of compensation for extra work.

URM HCWs also explained that they were asked to add diversity and inclusion work to their workload without compensation, which we described as the Minority Task theme. ${ }^{35}$ A male, Black/African American HCW explained:

Continued undervaluing of my achievements at work. Asked to do work for free on George Floyd. Had to take on the work on racial justice in the department for free. Passed over for major department role.

By being asked to discuss instances of police killings, e.g., of George Floyd, as a "teaching moment" for hospital staff, Black/African American HCWs dedicate their time to unpaid diversity work, which hinders their ability to pursue other areas of interest and even promotions.

Another theme that URM HCWs described was White Provider Preference, based on their experiences with patients who preferred to be cared for by White HCWs. This was particularly true among URM physicians, as patients questioned their competency and did not recognize them as "real doctors" even after repeatedly explaining their role. A female, Hispanic/Latino(a) attending physician described:

During virtual visits or phone calls to patients' family members I was told they wanted to talk to a 'real doctor' - that they were 'tired of talking to another foreign doctor that knows nothing...'

Another theme that HCWs described was External Structural Racism, which encompassed discrimination by institutions outside of the hospital, such as law enforcement. Black/ African American respondents reported heightened fear of violence due to the publicized murders of Blacks/African Americans, suggesting potential vicarious discrimination. A female, Black/African American HCW described:

I was stopped by a police officer and asked to show two forms of ID in order to be let go. This happened around the time of George Floyd's death so was very triggered by this experience.

\section{Experienced Discrimination Among Asian HCWs}

Many Asian HCWs reported experiencing discrimination due to rhetoric that blamed the pandemic on Asian people, which we termed the Pandemic-Related Discrimination theme. Some Asian HCWs reported that patients did not want to receive care from them due to fear that the provider's race and/or ethnicity would increase their risk of contracting COVID-19. A female, Asian HCW described:

I have had patients reluctant to have me be their anesthesiologist because of my Asian ethnicity and afraid that I may give them COVID. Someone else ended up taking over the case. It was frustrating.

Asian HCWs also described increased discrimination outside of the hospital and fear of hate crimes due to the pandemic, suggesting vicarious discrimination. A female, Asian HCW explained:

I was warned by my parents to not make a fuss if someone else was not wearing a mask due to reports of violence against people of Asian descent.

This respondent suggests that she is reluctant to protect herself from COVID-19 by asking people to wear masks due to anti-Asian violence. Thus, the respondent took on competing stressors related to risk of infection and anti-Asian violence.

Asian HCWs also described instances of discrimination aside from the pandemic that fell into the Microaggressions theme. For example, some reported that their colleagues would confuse them for another Asian colleague, which made them feel unrecognized and unappreciated.

\section{Experienced Discrimination Among Non- Hispanic White HCWs}

Non-Hispanic White HCWs suggested that they faced discrimination due to the recent racial justice movement. Some non-Hispanic White HCWs described their belief that racial injustices against people of color happened in the past without acknowledging the present violence against communities of color, a theme we termed Racism Denialism. A female, nonHispanic White, HCW described:

In general, the current racial awareness movement has portrayed white people as racists and have been also held responsible for racial injustices that have happened in the very distant past.

Non-Hispanic White HCWs also reported that their nonWhite patients thought they were racist and provided inferior care to them, which constituted the Perceived "White Victimhood" theme. Notably, White HCWs who reported discrimination by patients did not acknowledge the present discrimination against patients of color perpetuated by HCWs. ${ }^{36}$ A non-Hispanic White, female, HCW described:

We had a patient accuse the white staff of treating her unfairly because of the color of her skin but with the 
same treatment didn't give the Spanish or African American staff a hard time.

Additionally, some HCWs mentioned experiences of Perceived "White Victimhood" when they did not qualify for programs that aimed to increase diversity. A non-Hispanic White, male HCW described:

I was not re-assigned to a national committee by the president of my society who highlighted her program of increasing gender, racial, and ethnic diversity in committees. I didn't fit her vision of diversity.

This HCW failed to acknowledge that diversity initiatives are purposively distributed based on equity, rather than equal$i t y$, due to the exclusion and underrepresentation of non-White HCWs in medicine.

\section{DISCUSSION}

We assessed racial and ethnic discrimination among HCWs during a period of heightened violence against communities of color. We identified the prevalence, perpetrators, and predictors of reporting discrimination quantitatively, and explored the lived experiences of discrimination qualitatively. Our findings underscore the necessity for hospital-wide initiatives to promote inclusion of HCWs of color.

Overall, $85.2 \%$ of HCWs of color reported experiencing racial and/or ethnic discrimination in the past year. Compared with non-Hispanic White HCWs, discrimination was most commonly reported by URM HCWs followed by Asian HCWs, similar to another study. ${ }^{10}$ We also found that social support needs were associated with reporting discrimination, similar to others. ${ }^{1}$ We did not identify significant differences in reporting discrimination based on gender within race categories (e.g., between URM males and females), although other studies have, ${ }^{1,7,13,14}$ perhaps because our intersecting identity categories for non-White HCWs included relatively small numbers of respondents. Additional studies are warranted that are powered to explore how the intersection of racial, ethnic, and gender identities influences discrimination.

Our study identified perpetrators of racial discrimination, with the most common among HCWs of color being patients. Our qualitative findings suggested that patient discrimination took the form of refusing care from URM and Asian HCWs due to their race and ethnicity, which made them feel frustrated that their competency was being questioned. Another qualitative study identified that care refusal from patients took an emotional toll on HCWs and that there was insufficient institutional support to respond to such acts. ${ }^{24}$ Thus, hospitals should ensure that they have the systems in place for $\mathrm{HCWs}$ to report workplace discrimination and receive appropriate support.
Our qualitative findings emphasized the nuanced experiences of discrimination based on HCW race and ethnicity and how these experiences related to the current context, specifically the apotheosis of the Black Lives Matter movement and pandemic-related discrimination against Asian Americans. For example, URM HCWs shared how the murder of George Floyd in 2020 influenced their own experiences of discrimination, from fear when being pulled over by the police to increased requests for unpaid diversity work. Asian HCWs also recounted an acute increase in discrimination against Asian HCWs during the COVID-19 pandemic due to national rhetoric that posited COVID-19 as the "China virus," similar to how Asian Americans were scapegoated during the San Francisco Plague in $1900 .{ }^{37}$ Our qualitative findings also suggested that HCWs of color experienced persistent forms of discrimination, distinct from the COVID-19 pandemic and racial justice movement. For example, URM HCWs reported unequitable promotion and compensation, similar to other findings. ${ }^{38}$ Asian HCWs also reported being regularly mistaken for other Asian HCWs, consistent with other studies. ${ }^{39}$ Additional research is needed to explore how the changing context following the pandemic and Black Lives Matter movement impacts discrimination experiences, as well as persistent forms of discrimination, to design and implement hospitalwide inclusion initiatives.

Lastly, our qualitative findings suggested that some nonHispanic White HCWs believed that racism "happened in the very distant past," and others believed that they were victims of racism. These beliefs contradict well-documented evidence that racism continues to negatively impact the health and wellbeing of people of color, ${ }^{8}$ including within the health system. ${ }^{1,36,40,41}$ Previous studies have identified that White Americans significantly overestimate current levels of racial economic equality, ${ }^{42,43}$ which could explain why some nonHispanic White HCWs reported that racism no longer exists and others perceived that they were victims of racism themselves. Another possible explanation could be White backlash, or the negative response of White people to the perceived progress of certain racial and ethnic groups. ${ }^{44}$ White backlash is a form of White supremacy and has been identified during previous movements in the US, such as affirmative action. ${ }^{44}$ White backlash among HCWs may perpetuate implicit and/or explicit racial biases from non-Hispanic White HCWs, which have been associated with inferior care for non-White patients. ${ }^{40,41}$ Our findings demonstrate the critical need for hospitals to respond to White backlash present among HCWs to mitigate harm to non-White HCWs and patients.

Our study has notable strengths and limitations. First, our use of quantitative and qualitative methods enabled us to better understand the breadth and depth of racial discrimination among HCWs. Additionally, our sample was representative of the gender, racial, and ethnic makeup of HCWs in the US; $71.3 \%$ of our participants were female and $68.7 \%$ were nonHispanic White, while $76 \%$ of US HCWs are female and $64.4 \%$ are non-Hispanic White. ${ }^{45,46}$ Yet, the relatively small 
number of racial and ethnic minorities in the sample prevented us from conducting within-group analyses and separating out the experiences of different URM groups. Furthermore, we excluded four HCWs who identified as non-binary or transgender due to insufficient statistical power to identify differences by gender identity; future studies should purposively recruit gender minority $\mathrm{HCWs}$ to understand their experiences of discrimination. We used sex-based indicators for gender, which could have contributed to mismeasurement of gender identity. Additional studies should use more appropriate descriptors for gender identity (e.g., man, woman, trans man, trans woman, gender non-conforming). We used convenience sampling and collected anonymous responses to encourage respondents to share their experiences openly. However, this sampling approach may limit the generalizability of the prevalence of racial and ethnic discrimination to all HCWs in the US. Due to the cross-sectional nature of the survey, we were unable to identify causal relationships, particularly between social support and discrimination.

\section{CONCLUSION}

We identified the predictors, perpetrators, and narrative experiences of racial and ethnic discrimination among HCWs during a time of significant racial tensions. Our results provide insights that can be used by hospitals to foster inclusion. For example, by hospitals committing to invest at least $3 \%$ of its budget to support ongoing diversity, equity, and inclusion work, conversations about race can be facilitated by experts who are appropriately compensated. ${ }^{47}$ There are also critical needs for institutions to provide better support systems for dealing with discrimination from patients, and systematically identify salary discrepancies by race and ethnicity. Additionally, programs that mitigate White backlash among HCWs, such as through hospital-wide education, ${ }^{48}$ are vital to mitigate harm to non-White HCWs and patients. We hope that our findings can be used by hospitals to promote an inclusive climate for all HCWs.

Acknowledgements: We would like to thank all the healthcare workers who distributed and took our survey. RH and SL received funding support from Yale University's COVID-19 Response Coordination Team. SL received funding from an Early-Career Research Fellowship from the Gulf Research Program of the National Academies of Sciences, Engineering, and Medicine. The content is solely the responsibility of the authors and does not necessarily represent the official views of Yale School of Medicine or the Gulf Research Program of the National Academies of Sciences, Engineering, and Medicine. The funders had no role in the study design; in data collection, analysis, and interpretation of data; in the writing of the articles; and in the decision to submit it for publication.

Corresponding Author: Rachel Hennein, BS; Department of Epidemiology of Microbial Diseases, Yale School of Public Health, Yale University, 60 College St, New Haven, CT 06511, USA (e-mail: Rachel. hennein@yale.edu).

\section{Declarations:}

Conflict of Interest: The authors declare that they do not have a conflict of interest.

\section{REFERENCES}

1. Filut A, Alvarez M, Carnes M. Discrimination toward physicians of color: a systematic review. J Natl Med Assoc. 2020;112(2):117-140.

2. Morrison E, Grbic D. Dimensions of diversity and perception of having learned from individuals from different backgrounds: the particular importance of racial diversity. Acad Med. 2015;90(7):937-945.

3. Phillips KW. How diversity works. Sci Am. 2014;311(4):42-47.

4. Truitt AR, Snyder CR. Racialized experiences of Black nursing professionals and certified nursing assistants in long-term care settings. $J$ Transcult Nurs. 2020;31(3):312-318.

5. Moceri JT. Hispanic nurses' experiences of bias in the workplace. $J$ Transcult Nurs. 2014;25(1):15-22.

6. Iheduru-Anderson $\mathbf{K}$. Barriers to career advancement in the nursing profession: perceptions of Black nurses in the United States. Nurs Forum. 2020;55(4):664-677.

7. Nunez-Smith M, Pilgrim N, Wynia M, et al. Health care workplace discrimination and physician turnover. J Natl Med Assoc. 2009;101(12): 1274-1282.

8. Williams DR, Lawrence JA, Davis BA. Racism and health: evidence and needed research. Annu Rev Public Health. 2019;40:105-125.

9. Nguemeni Tiako MJ, South EC, Ray V. Medical schools as racialized organizations: a primer. Annals of Internal Medicine. 2021.

10. Nunez-Smith M, Pilgrim N, Wynia M, et al. Race/ethnicity and workplace discrimination: results of a national survey of physicians. $J$ Gen Intern Med. 2009;24(11):1198-1204.

11. Peterson NB, Friedman RH, Ash AS, Franco S, Carr PL. Faculty selfreported experience with racial and ethnic discrimination in academic medicine. Journal of General Internal Medicine. 2004; 19(3):259-265.

12. Pololi LH, Evans AT, Gibbs BK, Krupat E, Brennan RT, Civian JT. The experience of minority faculty who are underrepresented in medicine, at 26 representative U.S. medical schools. Acad Med. 2013;88(9):13081314.

13. Hassouneh D, Lutz KF, Beckett AK, Junkins Jr EP, Horton LL. The experiences of underrepresented minority faculty in schools of medicine. Medical education online. 2014;19(1):24768.

14. Pololi L, Cooper LA, Carr P. Race, disadvantage and faculty experiences in academic medicine. Journal of general internal medicine. 2010;25(12): 1363-1369.

15. Stop AAPI Hate. New Data on Anti-Asian Hate Incidents Against Elderly and Total National Incidents in 2020. 2021.

16. Ater R. In Memoriam: I Can’t Breathe. 2020; https://www.reneeater. com/on-monuments-blog/2020/5/29/in-memoriam-i-cant-breathe.

17. Bor J, Venkataramani AS, Williams DR, Tsai AC. Police killings and their spillover effects on the mental health of Black Americans: a population-based, quasi-experimental study. The Lancet. 2018;392(10144):302-310.

18. Umaña-Taylor AJ, Tynes BM, Toomey RB, Williams DR, Mitchell KJ. Latino adolescents' perceived discrimination in online and offline settings: an examination of cultural risk and protective factors. Developmental psychology. 2015;51(1):87.

19. Kwaning KM. Being Black in medicine in the midst of COVID-19 and police violence. Academic Medicine. 2020;95(12):1787-1788.

20. Miu AS, Moore JR. Behind the masks: experiences of mental health practitioners of color during the COVID-19 pandemic. Academic Psychiatry. 2021

21. Dong E, Du H, Gardner L. An interactive web-based dashboard to track COVID-19 in real time. Lancet Infect Dis. 2020;20(5):533-534.

22. Association of American Medical Colleges. Underrepresented in Medicine Definition. 2021; https://www.aamc.org/what-we-do/diversity-inclusion/underrepresented-in-medicine.

23. Landrine H, Klonoff EA, Corral I, Fernandez S, Roesch S. Conceptualizing and measuring ethnic discrimination in health research. $J$ Behav Med. 2006;29(1):79-94.

24. Wheeler M, de Bourmont S, Paul-Emile K, et al. Physician and trainee experiences with patient bias. JAMA internal medicine. 2019;179(12):1678-1685.

25. National Health and Nutrition Examination Survey. https://wwwn.cdc. gov/nchs/nhanes/Search/variablelist.aspx?Component=Questionnaire. Accessed October 17, 2020.

26. Ohman-Strickland PA, John Orzano A, Nutting PA, et al. Measuring organizational attributes of primary care practices: development of a new instrument. Health Serv Res. 2007;42(3 Pt 1):1257-1273.

27. Graetz I, Reed M, Shortell SM, Rundall TG, Bellows J, Hsu J. The association between EHRs and care coordination varies by team cohesion. Health Serv Res. 2014;49(1 Pt 2):438-452. 
28. von Elm E, Altman DG, Egger M, Pocock SJ, Gøtzsche PC Vandenbroucke JP. Strengthening the Reporting of Observational Studies in Epidemiology (STROBE) statement: guidelines for reporting observational studies. BMJ. 2007;335:806.

29. Tong A, Sainsbury P, Craig J. Consolidated Criteria for Reporting Qualitative Research (COREQ): a 32-item checklist for interviews and focus groups. International Journal for Quality in Health Care. 2007; 19(6):349-357.

30. Strauss A, Corbin J. Basics of Qualitative Research Techniques. Citeseer; 1998.

31. Kurasaki KS. Intercoder reliability for validating conclusions drawn from open-ended interview data. Field methods. 2000;12(3):179-194.

32. Braun V, Clarke V. Using thematic analysis in psychology. Qualitative research in psychology. 2006;3(2):77-101

33. Hall WA, Callery P. Enhancing the rigor of grounded theory: incorporating reflexivity and relationality. Qualitative health research. 2001;11(2):257-272.

34. Sue DW, Capodilupo CM, Torino GC, et al. Racial microaggressions in everyday life: implications for clinical practice. American psychologist. 2007;62(4):271.

35. Rodriguez JE, Campbell KM, Pololi LH. Addressing disparities in academic medicine: what of the minority tax? BMC Medical Education 2015; 15(1): 1-5

36. Washington HA. Medical Apartheid: the Dark History of Medical Exper imentation on Black Americans from Colonial Times to the Present. Doubleday Books; 2006.

37. Tansey T. Plague in San Francisco: rats, racism and reform. Nature. 2019;568:454-455

38. Nunez-Smith M, Ciarleglio MM, Sandoval-Schaefer T, et al. Institu tional variation in the promotion of racial/ethnic minority faculty at US medical schools. Am J Public Health. 2012;102(5):852-858.
39. Lin LC. A synthesis of the literature on Asian nurses' work experiences in the United States. Res Theory Nurs Pract. 2009;23(3):230-245.

40. Green AR, Carney DR, Pallin DJ, et al. Implicit bias among physicians and its prediction of thrombolysis decisions for Black and White patients. Journal of general internal medicine. 2007;22(9):1231-1238.

41. Chapman EN, Kaatz A, Carnes M. Physicians and implicit bias: how doctors may unwittingly perpetuate health care disparities. Journal of general internal medicine. 2013;28(11):1504-1510.

42. Kraus MW, Rucker JM, Richeson JA. Americans misperceive racial economic equality. Proceedings of the National Academy of Sciences. 2017;114(39): 10324-10331.

43. Kraus MW, Onyeador IN, Daumeyer NM, Rucker JM, Richeson JA. The misperception of racial economic inequality. Perspectives on Psychological Science. 2019;14(6):899-921.

44. Hewitt R. White Backlash and the Politics of Multiculturalism. Cambridge University Press; 2005.

45. U.S. Census Bureau. 2000 Census and 2017 American Community Survey 1-year estimates. 2017; https://www.census.gov/programs-surveys/acs/.

46. Bureau of Labor Statistics. State Occupational Employment Statistics Survey. 2018; http://www.bls.gov/oes/tables.htm.

47. Boatright $\mathbf{D}$, Berg $\mathbf{D}$, Genao I. A roadmap for diversity in medicine during the age of COVID-19 and George Floyd. Journal of General Internal Medicine. 2021.

48. Crear-Perry J, Maybank A, Keeys M, Mitchell N, Godbolt D. Moving towards anti-racist praxis in medicine. Lancet. 2020;396(10249):451453

Publisher's Note: Springer Nature remains neutral with regard to jurisdictional claims in published maps and institutional affiliations. 